\section{Information on COVID-19 vaccines and vaccinations}

\author{
Stephanie Kohl
}

Over the last weeks and months, a lot has happened in relation to the availability of COVID-19 vaccines. The European Medicines Agency (EMA) issued conditional marketing authorisations and held two public meetings informing about the vaccine processes. To ensure that hospital pharmacists receive all the latest information, EAHP has added a section on COVID-19 vaccines to its COVID-19 Resource Centre which can be accessed via the following link: https:// www.eahp.eu/hp-practice/hospital-pharmacy/eahp-covid-19-resource-centre.

The information in EAHP's COVID-19 Resource Centre includes materials prepared by the EMA and for the European Vaccination Information Portal. Hospital pharmacists will be directed to key facts, information on the development, evaluation, approval and monitoring of COVID-19 vaccines and their studies for approval as well as all information that can be made publicly available for conditionally authorised products.

The European Commission's webpage on 'Safe COVID-19 vaccines for Europeans' outlines how two billion doses of the vaccine have been secured for the EU, provides information about vaccination and shares advice from experts. In light of the recently approved COVID-19 vaccines, the European Commission has also made available Questions and Answers on COVID-19 vaccination in the EU.

To provide accurate, objective, up-todate evidence on vaccines and vaccination in general, the European Centre for Disease Prevention and Control, the European Medicines Agency and the European Commission created the 'European Vaccination Information Portal (EVIP)' earlier this year. This website outlines the mechanisms in place in the European Union to ensure that available vaccines conform to the highest standards of safety and effectiveness. Recently a specific webpage on COVID-19 vaccines was added. The webpage shares information on the activities of the European Commission, COVID-19 vaccines and facts about the pandemic. Concerning the COVID-19 vaccines, details on how they work, are

Correspondence to Stephanie Kohl, Policy \& Advocacy, European Association of Hospital Pharmacists, Brussels 1200, Belgium; Stephanie.Kohl@ eahp.eu developed and how their safety is monitored are being provided.

\section{PUBLIC CONSULTATION FOR THE EU LEGISLATION ON BLOOD, TISSUES AND CELLS LAUNCHED}

The European Commission has launched a public consultation for the European legislation on blood tissues and cells. The initiative aims to update the legislation to provide a more flexible alignment with scientific and technological developments, to tackle the (re-)emergence of communicable diseases, including lessons learnt from the COVID-19 pandemic and to focus on the increasing commercialisation and globalisation of the sector. Feedback can be shared until 15th of April 2021.

The EU legislation on blood, tissues and cells ensures safety and quality of these substances used every day to treat patients, in transfusion, cell and tissue transplantation or medically assisted reproduction. The donations are also critical for the manufacture of certain medicines. The current legislation was evaluated by the European Commission and the results were published in October 2019. The evaluation concluded that the legislation had effectively improved the safety and quality of these substances in the EU but it identified several shortcomings and gaps. Those included, for example, incomplete protection of EU citizens (patients, donors and offspring from medically assisted reproduction), difficulties to offer innovative therapies to patients and challenges to the sufficiency of supply of these substances.

To address those issues, the Commission has proposed policy options and other measures, which are described in the roadmap document. This consultation allows the public to express their views on these options. The feedback received will help the European Commission to elaborate and propose a revised up-to-date and better fit-for-purpose legislation on blood, tissues and cells.

\section{PORTUGAL TAKES OVER THE PRESIDENCY OF THE COUNCIL OF THE EU}

On first of January 2021, Portugal took over the Presidency of the Council of the EU from Germany. In the next 6 months emphasis will be put on bringing the EU through the COVID-19 pandemic and the promotion of a vision of the EU that is innovative, looks to the future and is based on common values of solidarity, convergence and cohesion.

In the health field, Portugal is planning to promote increased cooperation between Member States and to support the measures needed to augment the response capability of health services to threats to public health. Also, the acceleration of digitalisation will play a role since Portugal seeks to encourage new digital solutions and strategies for the green transition in the field of health.

\section{COUNCIL CONCLUSIONS ON COVID-19} RELEASED

In December 2020, the European Council approved conclusions which draw on the lessons learnt from the COVID-19 pandemic. These touch on improving crisis management, ensuring the supply of medicinal products, strengthening the EU's role in global health and improving access to and sharing of health data.

The Council conclusions pick up on initiatives that have already been started by the European Commission to improve crisis management and preparedness in the EU. To better ensure the supply of medicinal products across the Union the Council invites the European Commission to reinforce existing EU level tools to collect information on the whole supply chain, such as sources of supply, global manufacturing sites for active pharmaceutical ingredients (API) and other pharmaceutical substances. Also, the possibilities of facilitating the maintenance in the $\mathrm{EU}$ and the relocation to the EU of API manufacturing sites for critical medicinal products should be explored.

The importance of sharing and accessing health data is also acknowledged and a link to the European Health Data Space (EHDS) is mentioned. For the creation of a functioning EHDS - which will contribute to the cross-border use and re-use of health data for better healthcare, better research, as well as better policy-making and regulatory activities in health - the Council calls on the collaboration of the European Commission, Member States, and all relevant stakeholders. Concerning the EU's role in global health, the conclusions remind about the responsibility of the $\mathrm{EU}$ to strengthen existing ties with the $\mathrm{WHO}$ as the leading and coordinating authority on global health.

\section{EDOM WEBINAR - RESOLUTION TO PROMOTE PHARMACEUTICAL CARE IN EUROPE}

In March 2020 the Council of Europe Resolution $\mathrm{CM} / \operatorname{Res}(2020)$ three on the implementation of pharmaceutical care for the benefit of patients and health services was adopted. To better illustrate its application 
the European Directorate for the Quality of Medicines \& HealthCare (EDQM) has released a webinar at the end of 2020.

The resolution aims at improving medication use and the quality of patient care across Europe. To address inadequate use of medicines which can lead to suboptimal patient outcomes pharmacists are encouraged to use their expertise and that of the pharmacy team to contribute to the appropriate use of medicines and health promotion, both locally and nationally. The guidance and recommendations of the resolution seek to provide health authorities across Europe with information on how the promotion and implementation of pharmaceutical care can be supported. The resolution can also be used by healthcare professionals and associations as a legal basis for the implementation of pharmaceutical care and related working methods in their daily activities.

\section{FIP - MEDICINES REVIEW TOOLKIT FOR PHARIMACISTS}

To help pharmacists tackle medication errors the International Pharmaceutical Federation (FIP) has created a toolkit for medicines use review services. The toolkit serves as a reference guide for implementing and conducting optimal medicines use reviews. It includes service implementation tools that can be directly applied or adapted for clinical practice at the patient level.

The work of FIP interlinks with the patient safety and medication-related harm initiative of the WHO which is also the focus of the third Global Patient Safety Challenge called 'Medication without harm'. This is a global initiative seeks to reduce medication-related harm in all countries by $50 \%$ within 5 years with three specific areas for commitment, namely in high-risk situations, in patients with polypharmacy, and at transitions of care.

FIP's toolkit provides information on the history of medication use reviews and their application in pharmacies across the world such as in Australia, Canada, Spain, Sweden, the UK and the US. Besides the impact of medication reviews, the toolkit also details how these services should best be implemented and which process should be followed.

\section{WHO INTERIM GUIDANCE ON HEALTH WORKFORCE MANAGED DURING THE PANDEMIC}

The WHO has published interim guidance on 'Health workforce policy and management in the context of the COVID-19 pandemic response'. The document consolidates early evidence and identifies recommendations to protect, support and empower health workers at individual, management, organisational and system levels. It outlines COVID-19 human resources for health policy options for decision-makers and managers responsible for the planning, recruitment, training, equipment, deployment, protection and management of the health workforce at national, subnational and facility levels and some parts are also directly relevant for educators, regulators, development partners and health workers themselves.

The creation of the interim guidance was triggered by the pre-existing health workforce challenges, including the shortages of healthcare workers, that many countries are globally facing, which have been further impacted by COVID-19. The guidance seeks to outline how the additional service delivery needs for managing the pandemic can be balanced with the need for preserving and enhancing access to essential health services. The guidance covers the following areas:

- Supporting and protecting health workers (ie, infection prevention and control, including use of and access to personal protective equipment; decent working conditions, including occupational health and safety; mental health and psychosocial support; and remuneration and incentives)

- Strengthening and optimising health workforce teams (eg, building competencies through education and training)

- Increasing capacity and strategic health worker deployment (eg, improving health worker availability through hiring and redeployment, and ensuring a supportive work environment, including a manageable workload)

- Health system human resources strengthening (eg, improving health workforce information systems, including to track health worker infections; assessment and planning of health workforce needs; and licensing and regulation reforms).

\section{JOINT EMA-HIMA STRATEGY}

In mid-December, the European Medicines Agency (EMA) and the Heads of Medicines Agencies (HMA) published their joint strategy. This document sets out the work of both agencies in the next 5 years with an emphasis on protecting public health at a time of rapid change. Specific focus is put on how the European medicines regulatory network can continue to enable the supply of safe and effective medicines that meet patients' needs in the face of challenges posed by ever-accelerating developments in science, medicine, digital technologies, globalisation as well as emerging health threats, such as the COVID-19 pandemic.

The joint strategy of EMA and HMA outlines the actions of both agencies in the following six priority areas:

1. the availability and accessibility of medicines;

2. data analytics, digital tools and digital transformation;

3. innovation;

4. antimicrobial resistance and other emerging health threats;

5. supply chain challenges; and

6. the sustainability of the network and operational excellence.

For each of these priority areas the main challenges were identified and topicrelated goals, including proposals for high-level objectives that might form the starting point of actions to address these goals, have been put forward. The European medicines regulatory network will review the strategy after 18 months to consider if the goals and objectives remain appropriate, and to adjust them if necessary, in the light of the changing environment and ongoing engagement with stakeholders.

\section{STATE OF HEALTH IN THE EU: REPORT \\ FOR 2020 RELEASED}

With the publication of the Health at a Glance: Europe 2020 report, the European Commission has kicked off the next cycle of its State of Health in the EU initiative. The report covers information on health status, risk factors for health, health expenditure, quality and access to care in 36 European countries. Additionally, 2 thematic chapters of high relevance for the EU's agenda have been added, focusing on air pollution and the COVID-19 pandemic.

On COVID-19 the report shares a preliminary assessment of the effectiveness of European countries' containment and mitigation measures, health systems capacity, testing strategies, measures to protect vulnerable groups and continuity of care for non-COVID patients. Policymakers are provided with high-quality evidence from which valuable lessons can be learnt, more effective policy interventions developed, and build more resilient health systems, both in the short and the long term.

The State of Health in the EU is a 2 year initiative undertaken by the European Commission that provides policymakers, 
interest groups, and health practitioners with factual, comparative data and insights into health and health systems in EU countries. The cycle is developed in cooperation with the Organisation for Economic Co-operation and Development (OECD) and the European Observatory on Health Systems and Policies.

\section{THE EU'S PHARMACEUTICAL STRATEGY - SEEKING TO OFFER AFFORDABLE, ACCESSIBLE AND SAFE MEDICINES FOR ALL}

At the end of November 2020, the European Commission published its Pharmaceutical Strategy for Europe which seeks to ensure that patients have access to innovative and affordable medicines and to support the competitiveness, innovative capacity and sustainability of the EU's pharmaceutical industry. The strategy is a component for building a stronger European Health Union, an initiative that is slowly taking shape.

The Strategy takes into account some of the lessons learnt from the COVID-19 pandemic and focuses on four areas, namely:

- Ensuring access to affordable medicines for patients and addressing unmet medical needs;

- Supporting competitiveness, innovation and sustainability of the EU's pharmaceutical industry and the development of high quality, safe, effective and greener medicines;

- Enhancing crisis preparedness and response mechanisms, diversified and secure supply chains as well as addressing medicines shortages; and

- Ensuring a strong EU voice in the world, by promoting a high level of quality, efficacy and safety standards.

Several legislative and non-legislative actions will be launched in the coming years to support the realisations of the actions set out in the Strategy. These include, among others, futureproofing the existing pharmaceutical legislation, fostering research and innovation, creating a robust digital infrastructure and revising the regulations on medicines for children and rare diseases.

\section{EXPERT OPINION ON THE \\ ORGANISATION OF RESILIENT HEALTH AND SOCIAL CARE FOLLOWING THE COVID-19 PANDEMIC}

The European Commission publicised the opinion of the Expert Panel on Effective Ways of Investing in Health on the organisation of resilient health and social care following the COVID-19 pandemic. The document outlines how health system resilience can be strengthened, maps needs of vulnerable patients at times of crisis and defines a blueprint for resilience testing of health systems.

The Panel received the mandate to look beyond the current crisis and to consider how health systems can be prepared better for threats similar to those of the current pandemic. The experts looked at several areas, including but not limited to workforce training, research, development and procurement, interprofessional and inter-sectoral collaboration as well as integrating information and communication technologies. The Panel's recommendations range from creating adaptive surge capacity, taking into account solidarity mechanisms within and across borders; investing in primary care and mental health; designing strategies to monitor and reduce disinformation; linking databases across systems and sectors, in line with an integrated whole-of-society approach; providing specific training on dealing with socially deprived and minority groups; to developing a resilience test toolkit and implementation methodology for health systems.

\section{OECD REPORT ON EMPOWERING THE HEALTH WORKFORCE}

To support the activities of the German Presidency of the Council of the European Union, the Organisation for Economic Co-operation and Development (OECD) put together a report outlining proposals for utilising digitalisation in healthcare. The report titled 'Empowering the health workforce - Strategies to make the most of the digital revolution' was released at the conference 'Digital Health 2020 - EU on the Move', organised on 11th November by the German Federal Ministry of Health.

The report explores on the one hand the unique opportunities offered by digital technologies to health systems. On the other hand, it looks at barriers and the current state of play of the digital transformation in health systems. Since updating the digital infrastructure, ensuring interoperability standards and enabling data sharing cannot transform the health sector on its own, the report has put forward strategies that seek to help healthcare workers make use of these tools. To this end, the report discusses how to engage and empower the health workforce to make the most of the digital revolution by:
- building trust in the benefits of digital health technologies among health workers and patients;

- ensuring that digital technologies truly meet the needs of health workers and their patients;

- advancing expertise and skills needed within the health sector for effective co-design, deployment, and use of digital health technologies;

- adapting payment systems and the organisation of work such that health workers can timely and effectively start using digital solutions and tools.

\section{FIP - POSITION STATEMENT ON EMERGING TECHNOLOGIES AND PHARMACY PRACTICE}

The International Pharmaceutical Federation (FIP) has outlined in a new position statement how pharmacists and pharmacy organisations can rise to the challenge that new technologies provide to the profession. By touching on current advancements, the statement shares insights on the work of pharmacists and their capability to deliver universal, safe, accessible and timely care with the help of digital technology.

The statement highlights technological advances, some which might be considered disruptive, that are affecting the pharmacy profession. These include for instance successfully providing remote services during the COVID-19 pandemic, 24/7 online access to pharmacists, harvesting of patient health and online purchasing data by profit-seeking entities and the use of artificial intelligence. The statement also insists on the need to involve pharmacists in the development of digital health technologies.

Funding The authors have not declared a specific grant for this research from any funding agency in the public, commercial or not-for-profit sectors.

Competing interests None declared.

Provenance and peer review Commissioned; internally peer reviewed.

(c) European Association of Hospital Pharmacists 2021. No commercial re-use. See rights and permissions. Published by BMJ.

$$
\text { D) Check for updates }
$$

To cite Kohl S. Eur J Hosp Pharm 2021;28:120-122.

Eur J Hosp Pharm 2021;28:120-122. doi:10.1136/ejhpharm-2021-002723

ORCID iD

Stephanie Kohl http://orcid.org/0000-0003-0324-7976 